\title{
AEROMAGNETIC MAP OF PART OF THE STAMFORD QUADRANGLE, FAIRFIELD COUNTY, CONNECTICUT
}

\author{
GEOPHYSICAL INVESTIGATIONS
}

MAP GP-826

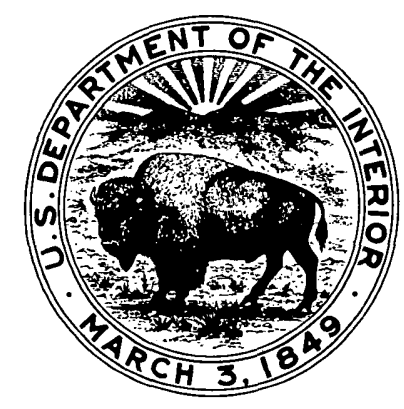

PUBLISHED BY THE U.S. GEOLOGICAL SURVEY 